"históricamente", fuera de la leyenda, el personaje en cuestión, imita el gracioso juego del minino haciendo cabriolas para moderse la cola, o la menos graciosa ocurrencia del loco que quiso pisar su propia sombra. "Don Manuel" se murió, desapareció, para pervivir como San Manuel Bueno. El testimonio de Ángela tiene el mismo valor cuando nos dice que San Manuel se llevaba las miradas de todos, o que ocultaba un secreto a sus feligreses, que cuando nos testifica que su Santo murió creyendo que no creía, pero creyendo en realidad. El autor, es decir, Unamuno, no interviene en el relato, directa ni indirectamente, y por ende no tenemos otra versión ni otra visión de las cosas que nos pueda servir de contraste. Es cosa diferente el juicio personal que nos merezca a nosotros la presunta fe o santidad del santo varón. Pero esto no nos autoriza para dedicarnos a indagar sin esperanzas de éxito, cómo era "en realidad" el Párroco o su iglesia, haciendo caso omiso del único testimonio que tenemos. Al igual que el lago y la montaña no es el Don Manuel de carne y hueso, el objeto del relato o memorias de Angela, sino el "otro", el "espiritual", el "que quedó" perviviendo en la memoria de las gentes.

Francisco Fernández-Turienzo

University of Massachusetts (Amherst).

\title{
LA COMPOSICIÓN DEL PERSONAJE EN LA FICCIÓN DE BORGES *
}

La falta de "realidad" en la obra de Borges -más precisamente en los personajes de Borges- es tópico de la crítica. Para Ernesto Sábato, Borges "construye cuentos en que fantasmas que habitan rombos o bibliotecas o laberintos no viven ni sufren sino de palabra" 1 . E1 juicio no podría ser más sensato: toda ficción, todo "mundo", todo "personaje", existe de palabra. La comprobación, sin embargo, se transforma en reproche cuando se la aplica a la obra de Borges: el personaje borgeano es juzgado prescindible, secundario, al fin de cuentas sometido a un relato, y eso está mal. No parece importar que el propio Borges haya hablado, en términos favorables, de esa desconsideración del personaje. En su ensayo sobre Nathaniel Hawthorne, sugiere Borges que Hawthorne "primero imaginaba, acaso involuntariamente, una situación y bus" caba, después, caracteres que la encarnaran". El método, añade Borges, "puede producir, o permitir, admirables cuentos, porque en ellos, en razón de su brevedad, la trama es más visible que los actores" 2.

Sin embargo, la posición de Borges ante el personaje literario dista de ser tan simple. Por un lado nos recuerda, siguiendo a Stevenson, que

* Conferencia pronunciada en Columbia University el 29 de octubre de 1973.

1 ERnesto Sábato, "Borges", Uno y el universo, Buenos Aires, 1968, pp. 21-26.

2 "Nathaniel Hawthorne", Otras inquisiciones, Buenos Aires, 1964, pp. 78-79. Abreviaré: $O I$. 
el personaje es un objeto verbal, una convención literaria, un artificio. Por otro, se permite declaraciones curiosas que parecerían justificar las opiniones de sus propios críticos. Dice Borges de Henry James: "Pienso que sus personajes apenas existen fuera del relato. Pienso que sus personajes no son reales" 3 . Habla Borges de los "reales" personajes de Dickens, de Conrad. Considera que el Billy Budd de Melville "es un hombre real" (Burgin, 70).

Quisiera comentar estas dos actitudes, aparentemente contradictorias, porque aclaran, creo, la concepción que tiene Borges del personaje literario. $\mathrm{Y}$ porque aclaran las técnicas que utiliza el escritor para presentar a ese personaje. Recurro a dos textos de Borges que pertenecen a sus "olvidables y olvidados" libros, Inquisiciones (1925) y El tamaño de mi esperanza (1926). En el primero incluye un ensayo, "La nadería de la personalidad", en el que declara, con el empaque retórico de su primera época:

Pienso probar que la personalidad es una transoñación, consentida por el engreimiento y el hábito, mas sin estribaderos metafísicos ni realidad entrañal. Quiero aplicar, por ende, a la literatura, las consecuencias dimanantes de esas premisas, y levantar sobre ellas una estética, hostil al psicologismo que nos dejó el siglo pasado... ${ }^{4}$

En este ensayo insiste Borges en corroer la concepción de una personalidad única con la cual sería posible identificarse, establecer una comunicación. Es imposible abarcar la personalidad del otro como es im. posible abarcar la personalidad propia:

Basta caminar algún trecho por la implacable rigidez que los espejos del pasado nos abren, para sentirnos forasteros y azorarnos cándidamente de nuestras jornadas antiguas. No hay en ellas comunidad de intenciones, ni un mismo viento que las empuja (ibid., 87).

Sin embargo el mismo Borges, el que niega la posibilidad de un destino único, el que niega la posibilidad de comunicación con el otro, consigo mismo, escribe un año más tarde, al comentar la novela $L a$ tierra cárdena de Guillermo Hudson:

[Es] el libro de un curioso de vidas [...]. Hudson nunca se enoja con los interlocutores del cuento, nunca los reta ni los grita ni pone en duda la verdad democrática de que el otro es un yo también y de que yo para él soy un otro y quizás un ojalá no fuera. [...] Así ha trazado inolvidables destinos [...]. Esos vivires y los que pasan por la fila de cuentos que se llaman Ei Ombú, no son arquetipos eternos; son episódicos y reales como los inventados por Dios. Atestiguarlos es añadirse vidas claras -nobles casi siempre, también- y enanchar el yo a muchedumbre 5 .

3 Richard Burgin, Conversations with Jorge Luis Borges, New York, 1970, p. 70. Abreviaré: Burgin.

4 Inquisiciones, Buenos Aires, 1925, p. 84.

5 "La tierra cárdena", El tamaño de mi esperanza, Buenos Aires, 1926, p. 35. 
O sea: por un lado hay el "curioso de vidas" (Borges, en su primer: poesía, se define como un "codicioso de almas"), el que se añade vida "reales" para "enanchar el yo a muchedumbre". Y por el otro, el inqui sidor del yo de conjunto que persiste en ver en cada yo, en cada perso nalidad, un conglomerado arbitrario de partículas irreconocibles. Entri estos dos polos oscila el personaje borgeano. No sólo los personajes di las ficciones de Borges, las que él mismo declara ficciones: pensemos er textos anteriores, en la biografía de Evaristo Carriego y en las "biogra fías infames" -así las llama Borges- de Historia universal de la infamia

El primer intento de ficción de Borges, Evaristo Carriego, es un; biografia. "Que un individuo quiera despertar en otro individuo recuer dos que no pertenecieron más que a un tercero, es una paradoja evi dente. Ejecutar con despreocupación esa paradoja es la inocente volun tad de toda biografía" ". Por lo tanto una ficción supuestamente cot un personaie central: Evaristo Carriego. Pero recordemos aquí el epí grafe del libro, tomado a De Ouincev: "A mode of truth, not of trutl coherent and central, but angular and splintered". Y recordemos el tip de personaie que fue Carriego. Cuenta Boroes en una entrevista que $\mathrm{l}_{\text {: }}$ elección del personaie fue deliberada (Burgin, 31). Se le había aconse jado escribir sobre Lugones. poeta "más interesante", sin duda poet: central; elige en cambio a Evaristo Carriego, poeta del arrabal, de l: periferia, poeta secundario, provinciano, lateral.

Este primer ejercicio narrativo de Borges ilustra los dos textos qu he ritado. Si buscamos el personaje cuva vida se narra, el "yo de con junto", no lo encontramos. El capítulo que en esta biografía supondría mos central - "Una vida de Evaristo Carrieoo"-- presenta a un perso naje perfilado por sombras. En cambio, en los otros capítulos, aparec un Carriego fragmentario, traducido a su periferia. "Los amigos, lo mis mo que los muertos y las ciudades, colaboran en cada hombre". (EC, 43) escribe Borges, v anota que Carriego "se sabia delicado y mortal, perc leguas rosadas de Palermo estaban respaldándolo" $(E C, 40)$.

En esa periferia se sitúa, justamente, la posibilidad de reconocimien to, de "realidad" que Borges alababa en la novela de Guillermo Hud son. No nos reconocemos - más bien no admitimos la realidad de $u$ r Carriego-- porque ese Carriego ha sido deliberadamente añicado. Perc reconocemos -o Borges nos invita a reconocer-gestos, actitudes insig nificantes, circunstancias que aluden al personaje, que lo incrustan: 1: copa grande de guindado oriental que bebe, el gajito de madreselva qui corta al orillar una tapia. El personaje queda fijado en sus rasgos aisla dos: los suyos o los que para él imagina el narrador.

El codicioso de almas, el curioso de vidas que es Borges en Evarist Carriego, se transforma en Historia universal de la infamia. Persisten l: codicia y la curiosidad, pero aplicadas de manera diferente. Historic universal de la infamia no relata vidas ajenas; es, como lo dice el misms Borges, "el irresponsable juego de un tímido que no se animó a escribi:

6 Evaristo Carriego, Buenos Aires, 1963, p. 33. Abreviaré: EC. 
cuentos y que se distrajo en falsear y tergiversar [...] ajenas historias" ?. El paso de la ajena vida a la ajena historia le permite a Borges desdeñar -descaradamente- al personaje, complacerse en el puro artificio. Dice de Historia universal de la infamia que:

Patíbulos y piratas [la] pueblan y la palabra infamia aturde en el título, pero bajo los tumultos no hay nada. No es otra cosa que apariencia, que una superficie de imágenes; por eso mismo puede acaso agradar (HUI, 10).

El personaje que aparece en Historia universal de la infamia es un personaje literalmente descarado: impostor, recurre a la máscara, a variadas máscaras. Apenas hay descripciones físicas. Lazarus Morell muere con un nombre falso, se niega durante su vida a quedar fijado en un daguerrotipo, "esencialmente para no dejar inútiles rastros, de paso para alimentar su misterio" (ibid., 21). El proveedor de iniquidades Monk Eastman se llama Edward Ostermann, alias Edward Delaney, alias William Delaney, alias Joseph Marvin, alias Joseph Morris, alias Monk Eastman. Y añade Borges:

Estas fintas graduales (penosas como un juego de caretas que no se sabe bien cuál es cuál) omiten su nombre verdadero -si es que nos atrevemos a pensar que hay tal cosa en el mundo (ibid., 56).

El caso más patente de impostura, en Historia universal de la infamia, es, desde luego, el del tintorero enmascarado. Falso profeta, se sabe que de joven fue adiestrado en el oficio de tintorero, "arte de impíos, de falsarios y de inconstantes" (ibid., 84). Leproso, se cubre con sucesivas máscaras que engañan a sus fieles hasta que uno de ellos se atreve a arrancarle el velo. Borges describe la cara que se ve entonces, la verdadera, la manchada de lepra: "era tan abultada o increíble que les pareció una careta" (ibid., 92) .

En términos generales, los personajes que presenta Borges en Evaristo Carriego y en Historia universal de la infamia -basados en ajenas vidas o en ajenas historias- resultan unidades esquivas. Fragmentados deliberadamente por el autor, alienados de un supuesto centro del relato mediante la importancia que cobran las proyecciones, escudados por máscaras, son, como dice Borges al hablar de Citizen Kane, "un simulacro, un caos de apariencias" 8.

Creo que ya a esta altura de la obra narrativa de Borges se plantean una serie de interrogantes sobre sus personajes. Hay que recordar, sin embargo, que ninguno de los textos comentados son, para el autor, ficciones. Borges escribe su primer relato en 1939 y recalca la ruptura deliberada: "Entonces decidí escribir algo, pero algo nuevo y diferente para mí, para poder echarle la culpa a la novedad del empeño si fra-

7 "Prólogo a la edición de 1954", Historia universal de la infamia, Buenos Aires, 1966, p. 10. Abreviaré: HUI.

8 "Un film abrumador", Sur, 1941, núm. 83, p. 88. 
casaba. Me puse a escribir ese cuento que se llama "Pierre Menard, autor del Quijote»".

Si el lector busca en "Pierre Menard" los elementos que tradicionalmente integran un relato queda más que defraudado. En esa ficción no pasa nada. Tampoco pasa nada, por ejemplo, en más de un relato de James. Pero en esta primera ficción de Borges se esfuman tanto la acción como su intérprete. Contrariamente a lo que declara Borges en su ensayo sobre Hawthorne -el escritor de cuentos parte de una situación y luego fabrica a un personaje que la encarne- "Pierre Menard" presenta una situación deliberadamente desencarnada. Más: deliberadamente textual. Un narrador presenta a un poeta, a un "llorado poeta" a quien conoció en un vendredi de la condesa de Bacourt y de quien se ha despedido "ante el mármol final y los cipreses infaustos" 10 . Por el tono mismo del narrador, cursi precursor de otros hommes de lettres borgeanos (Carlos Argentino Daneri, Gervasio Montenegro), aceptaríamos sin mayor esfuerzo a Pierre Menard, meritorio poeta francés, simbolista, provinciano. La bibliografía que a continuación nos da Borges de Pierre Menard contribuye a desubicarlo totalmente. Menard, además de un ciclo de sonetos para la baronesa de Bacourt, de una colaboración con Gabriele d'Annunzio, de una invectiva contra Paul Valéry, de un soneto que apareció dos veces (con variaciones) en la revista La conque, resulta ser, como por añadidura, autor de una monografía sobre la posibilidad de construir un vocabulario poético donde no hubiera "sino objetos ideales creados por una convención y esencialmente destinados a las necesidades poéticas" $(F, 46)$, de una monografía sobre el pensamiento de John Wilkins y de una discusión sobre las aporías eleáticas: tres temas sobre los que escribirá más tarde el propio Borges. $\mathrm{Y}$ además, desde luego, este mediocre o no tan mediocre poeta simbolista de Nîmes, de quien se nos da una "historia mental" pero ningún rasgo físico - volvemos a la máscara, en este caso una máscara de textos- es el nuevo autor del Quijote y menos desdeñable de lo que podría creerse puesto que propone al final del relato una de las ideas claves de Borges: la de enriquecer "mediante una técnica nueva el arte detenido y rudimentario de la lectura: la técnica del anacronismo deliberado y de las atribuciones erróneas" (ibid., 56) .

Esta primera ficción declarada de Borges no sólo nos insta, como dice su autor, "a recorrer la Odisea como si fuera posterior a la Eneida y el libro Le jardin du Centaure de Madame Henri Bachelier como si fuera de Madame Henri Bachelier" (loe. cit.). Nos insta, creo, a contem. plar la posibilidad de un personaje innecesario, mero nexo $-y$ no el único- entre los motivos de la narración. Nos insta además a desconfiar saludablemente del narrador, tan inconsistente como el personaje que propone. Personaje y narrador pierden textura individual a medida que la va cobrando el relato. Lo que más importa en "Pierre Menard" es por cierto una situación -podríamos llamarla la nadería de la autori-

9 James E. Irby, Encuentro con Borges, Buenos Aires, 1968, p. 37.

10 Ficciones, Buenos Aires, 1963, p. 45. Abreviaré: $F$. 
dad- y narrador y narrado, fieles a esa situación, no llegan nunca a encarnarse en ella, a proponer una imagen, un estilo único.

Me detengo en esta primera ficción de Borges para recalcar la textualidad de su personaje, obvia en la mayoría de sus relatos. Alguna vez se ha descrito a Hamlet como un pobre joven con un libro en la mano. Con un libro en la mano -que leen, que escriben, del que son intérpretes- están la mayoría de los personajes de Borges. De la lectura del tomo duodécimo de la Civitas Dei surgen Aureliano y Juan de Panonia en "Los teólogos", de la página 278 de la Poesia de Croce el Droctulft de "Historia del guerrero y de la cautiva". En dos de sus avatares es escritor el personaje -si así puede llamárselo- de "El inmortal": cuando es Homero y cuando es Joseph Cartaphilus, escriba de "El inmortal". Dahlmann, en "El sur", es lector y bibliotecario. Averroes, escritor y traductor. En "La muerte y la brújula" se enfrentan dos lectores: triunfa el más complejo, Scharlach, lector de los textos hasídicos y lector de la lectura que de esos mismos textos hace Lönnrot. En "El jardín de senderos que se bifurcan" dos personajes se enfrentan ante un texto: muere Albert, lector del laberinto escrito por Ts'ui Pen, y mediante esa muerte el espía, Yu Tsun, escribe "el nombre secreto de la ciudad" para sus jefes alemanes.

Borges ha escrito más de una vez que la transcripción de la realidad es una ilusión más de la llamada literatura realista "porque la realidad no es verbal" 11. Estas lecturas de los personajes borgeanos que menciono, estas actividades literarias, son algo más que actividades circunstanciales: de algún modo operan como caracterización emblemática, son señalamiento expreso de lo que forma y destruye a los personajes. "La certidumbre de que todo está escrito nos anula o nos afantasma" 12, escribe Borges, que también recuerda la hipótesis de Léon Bloy: los hombres son "versículos o palabras o letras de un libro mágico, y ese libro incesante es la única cosa que hay en el mundo: es, mejor dicho, el mundo" ${ }^{13}$. Esa textualidad del personaje cumple, en la obra de Borges, la misma función que sus citas eruditas. Son signos manifiestos de que el lector está "en literatura" así como el espectador sabe que está "en el teatro" al ver la representación del actor chino que comenta Brecht.

A partir de "Pierre Menard", la textualidad es una de las técnicas que usa Borges para inquietar la aceptación beata del personaje único y coherente. Sin embargo la mascarada, usada tan libremente en Historia universal de la infamia, no desaparece en las ficciones posteriores: se recurre a ella de manera más sutil. Disminuyen a partir de "Pierre Menard" las referencias explícitas a las máscaras, simplemente porque ya no se sabe cuál es el rostro y cuál es la máscara. Los dos se confunden, se funden en la trama, como se confunden los relatos adventicios de Las mil y una noches con el relato que los contiene: "las antesalas se confunden con los espejos, la máscara está debajo del rostro, ya nadie

11 "Quevedo", $O I, 61$.

12 "La biblioteca de Babel", $F, 94$.

13 "Del culto a los libros", $O I, 163$. 
sabe cuál es el hombre verdadero y cuáles sus ídolos" 14. Para la divinidad los teólogos Aureliano y Juan de Panonia son una sola persona o una misma nada. El guerrero y la cautiva son protagonistas de una misma historia: "El anverso y el reverso de esta moneda son, para Dios, iguales" ${ }^{15}$. En "Las ruinas circulares" tanto el hombre gris como el ser soñado son "meros simulacros", y en el poema "El golem" tanto el rabino como su deficiente creación padecen de irrealidad. Proceden, diría Borges, de la diversa entonación de una misma metáfora; de una misma metáfora "o simulacro" 16 .

Más que la busca del doble -finalmente poco eficaz para explicar al personaje de Borges, que se divide en dos, que se diyide en tres, que se añica -interesa la rara avidez que Borges atribuye a sus personajes, a esas partículas de personaje ilusoriamente singulares. Parecería resurgir el "codicioso de almas" (de comportamientos, de detalles) en "Abenjacán el Boharí, muerto en su laberinto", en "La muerte y la brújula", en "El muerto", en "El fin". Pero lo que Borges veía, como posibilidad alentadora, al leer la novela de Hudson - "añadirse vidas claras", enriquecerse con destinos únicos, "enanchar el yo a muchedumbre"- aparece años más tarde cambiado de signo. Zaid mata a Abenjacán para ser Abenjacán; pero finalmente es "un vagabundo que, antes de ser nadie en la muerte, recordaría haber sido un rey o haber fingido ser un rey algún día" $(A, 134)$. Cuando en "El fin" el negro mata a Martín Fierro, cuando se añade el destino único de Martín Fierro, "volvió a las casas con lentitud, sin mirar para atrás. Cumplida su tarea de justiciero, ahora era nadie. Mejor dicho era el otro: no tenía destino sobre la tierra y había matado a un hombre" $(F, 180)$. Y el inmortal, al añadirse, y padecer infinitas vidas, descubre que:

nadie es alguien, un solo hombre inmortal es todos los hombres. Como Cornelio Agripa, soy dios, soy héroe, soy filósofo, soy demonio y soy mundo, lo cual es una fatigosa manera de decir que no soy $(A, 21)$.

Hasta aquí he presentado a un personaje borgeano minado, atacado, derruido. Un personaje tal como describe el propio Borges a los personajes de Henry James, "hecho para la trama, al servicio de la trama" (Burgin, 70). Un personaje, según la descripción de Nathalie Serraute, "despojado de todas sus prerrogativas, de su carácter, reducido a un simple trompe-l'oeil, una sobrevivencia, un soporte incidental" 17. Así funcionan por cierto Pierre Menard, fabricado a base de lecturas y de obras dispares en función de una teoría del ejercicio literario. O Emma Zunz, sostén de actos diversos que por un momento -el de la lectura de "Emma Zunz"- constituyen una acción. O el gaucho que en "La trama" "no

14 "Los traductores de las $100 \mathrm{I}$ noches", Historia de la eternidad, Buenos Aires, 1965, p. 133.

15 El aleph, Buenos Aires, 1963, p. 52. Abreviaré: $A$.

16 "El *Biathanatos"", OI, 131.

17 Nathalie Sarraute, "Ce que je cherche à faire", Noveau roman: hier, aujourd'hui, t. 2, Paris, 1972, p. 26. 
sabe que muere para que se repita una escena" ${ }^{18}$, la del asesinato de Julio César.

Greo que el personaje borgeano es algo más. $\mathrm{O}$ mejor dicho creo que Borges quiere, muy deliberadamente, que su personaje sea algo más. El postulador de la nadería de la personalidad añora destinos claros, los "reales" personajes de Melville. Pienso que la misma ambigüedad se encuentra en los ensayos de Borges. Por un lado elogia a Valéry como "un hombre que trasciende los rasgos diferenciales del yo y de quien podemos decir, como William Hazlitt de Shakespeare, He is nothing in himself" ${ }^{19}$. Por otro lado se empeña en rescatar, a contracorriente, destinos, datos individuales. Dice que "ninguna criatura de Flaubert es real como Flaubert" ${ }^{20}$. O que "la definición roseau pensant no nos ayuda a comprender a los hombres pero sí a un hombre, Pascal" ${ }^{21}$.

El deseo de dar "realidad" al personaje narrativo aparece en Borges junto a la tendencia, imperiosa, de irrealizarlo. Desdeña el estilo de la realidad -lo que llama la "prolijidad de lo real"-, desdeña la mo. rosidad de la novela realista. Pero, por otra parte, se reserva la posibilidad de introducir jirones de esa realidad, de una ilusión de realidad, para incrustar a su personaje, y lo hace sorpresivamente, rechazando la "concatenación de motivos que se proponen no diferir de los del mundo real" 22 .

"La postulación clásica de la realidad -escribe Borges- puede asumir tres modos, muy diversamente accesibles". El primero, al que no parece adjudicar mucha importancia, "consiste en una notificación general de los hechos que importan". El segundo, en "imaginar una realidad más compleja que la declarada al lector y referir sus derivaciones"; el tercero, en ejercer "la invención circunstancial" ${ }^{23}$. Un análisis apenas atento de estos modos quizá desconcierte al lector, puesto que los tres, en resumidas cuentas, pueden reducirse a la primera fórmula: una notificación de "los hechos que importan". La diferencia reside, creo, en una variada acentuación. Si el primer método no despierta mayor interés por parte de Borges, bien podría ser porque se trata, como él mismo dice, de una notificación general. Si se detiene en el comentario de los dos siguientes es sin duda porque le proponen, en grado diverso, la posibilidad de una notificación particular. Y esa notificación - por su carga de asombro o por su elegancia (suelen coincidir los dos términos en la obra de Borges) - dan al relato y a su personaje esa "realidad" -esa verosimilitud, esa eficacia literaria- que para ellos reclama.

Es significativo que Borges se detenga, con evidente delectación, en el tercer método que propone, el de la invención circunstancial. Lo llama "el más difícil y eficiente de todos" y cita para ilustrarlo "cierto

18 El hacedor, Buenos Aires, 1960, p. 28.

19 "Valéry como símbolo", $O I, 107$.

20 "Flaubert y su destino ejemplar", Discusión, Buenos Aires, 1964, p. 149. Abreviaré: $D$.

21 "Pascal", OI, 135.

22 "El arte narrativo y la magia", $D, 88$.

23 "La postulación de la realidad", $D, 71-72$. 
memorabilísimo rasgo de La gloria de Don Ramiro: ese aparatoso caldo de torrezno, que se servía en una sopera con candado para defenderlo de la voracidad de los pajes". "Tan insinuativo - añade Borges- de la miseria decente, de la retahila de criados, del caserón lleno de escaleras y vueltas y de distintas luces" $(D, 72)$. Con esa sopera concreta, minuciosamente rescatada de lo que Henry James llamaba "el magnífico desperdicio de la realidad" - es decir, minuciosamente imaginada dentro de ese desperdicio-, Larreta fija una atmósfera y fija también a esos personajes episódicos, insignificantes, que son los pajes de Iñigo de la Hoz.

Antes de analizar el empleo deliberado que hace Borges de la invención circunstancial, quiero detenerme en las declaraciones de uno de sus precursores, Robert Louis Stevenson, a quien se refiere más de una vez, directa o indirectamente. Como Borges, desdeña Stevenson al personaje literario y declara la supremacía de la situación o de lo que él llama el incidente. Coarta la siempre dispuesta simpatía del lector recordándonos que los personajes son títeres "con caras de madera, con vientres de aserrín", que "son siempre ellos mismos, no son nosotros", que la descripción "realista" del personaje sólo puede proporcionarnos un placer crítico. El desdén al que somete Stevenson al personaje literario, a sus propios personajes, es sin duda menos complejo que el que hemos visto en Borges. Los desdeña de plano, no nos hace ver, como Borges, las etapas de la descomposición. Pero, al igual que Borges, se detiene en el "encanto de lo circunstancial", en el detalle eficaz que de pronto fija el relato $y$ fija al personaje. Cito de "A gossip on romance":

Las hebras de un relato se unen cada tanto para formar un diseño en la trama; los personajes adoptan cada tanto una actitud -ante los otros, ante la naturaleza- que graba el relato [stamps the story home] como una imagen. Crusoe sobresaltado ante la huella de un pie, Aquiles gritando por encima de las voces de los troyanos, Ulises al combar el gran arco, Christian que huye tapándose los oídos con las manos: momentos culminantes de la leyenda, cada uno de ellos queda impreso para siempre en la mente. Podremos olvidar otras cosas: olvidaremos las palabras, por bellas que sean; olvidaremos el comentario del autor, aunque haya sido ingenioso y exacto; pero adoptamos tan intimamente estas escenas memorables que dan el último toque de verosimilitud al relato y colman, de golpe, nuestra capacidad de goce simpático, que ya nada podrá borrar o debilitar esa impresión. Es esa la función plástica de la literatura: dar cuerpo al personaje, al pensamiento, a la emoción, por medio de algún hecho o de alguna actitud que cautive de manera notable nuestra mente 24 .

Dar cuerpo al personaje, dice Stevenson. Creo que la invención cir. cunstancial, tal como la entienden Stevenson y Borges, culmina en la obra de Borges en una retórica gestual del personaje, compuesta de actitudes que fueron quizás insignificantes, que resultan definitorias. Pienso en algunas críticas de cine de Borges. Del film El delator retiene, por

21 "A gossip on romance", Memories and portraits, en The works of Robert Louis Stevenson, t. 6, New York, s. f., pp. 119-131. 
ejemplo, "el raspar final de las uñas en la cornisa y la desaparición de la mano, cuando al hombre pendiente lo ametrallan y se desploma" 25 . De Los hermanos Karamazov de Ozep recuerda Borges "la mano clerical de Smerdiakov, retirando el dinero" ${ }^{26}$. Ya había detalles, gestos de este tipo en Historia universal de la infamia: recordamos de Monk Eastman -a pesar de la serie de pseudónimos que lo esconden- que se paseaba siempre con una paloma azul en el hombro.

El gesto circunstancial que rescata Borges para su personaje puede ser simbólico: así por ejemplo, en "Biografía de Tadeo Isidoro Cruz". Cruz, al reconocer su destino, al comprender que el otro -Martín Fierro- era él, arroja por tierra su quepis y con ese gesto indica su elección, su cambio de vida. Pero en el mismo relato Borges nos indica un gesto igualmente eficaz, aunque aparentemente menos revelador. Cruz está herido, sigue luchando, y -dice Borges- "cuando la sangre le corrió entre los dedos, peleó con más coraje que nunca" $(A, 54)$. Aquí Borges recuerda un gesto circunstancial ya recogido por otro autor: uno de los personajes de Pilgrim's Progress declara que "cuando la sangre me corrió entre los dedos peleé con más coraje que nunca". No importa el préstamo, sí importa el gesto incidental que, como diría Stevenson, "stamps the story home".

Lo mismo ocurre en "El fin". Borges imagina la venganza del negro a quien Martín Fierro ha derrotado doblemente: primero matando a su hermano, luego venciéndolo en un duelo oral. El negro, en el relato de Borges, mata a Martín Fierro. Luego, dice Borges, "limpió el facón ensangrentado en el pasto y volvió a las casas con lentitud, sin mirar para atrás" $(F, 180)$. El mismo detalle ya aparecía en el poema de Hernández: es el gesto del propio Martín Fierro cuando mata al hermano del negro.

Los gestos y detalles de este tipo, obviamente cargados de referencia, son frecuentes en Borges. Me interesan más los gestos menos obvios y -para mí- igualmente realizadores. Por ejemplo, los gestos de $\mathrm{Yu}$ Tsun, en "El jardín de senderos que se bifurcan": antes de salir para matar a Albert, se mira en el espejo. En el mismo cuento, poco antes: recorre el contenido de sus bolsillos, encuentra una carta, decide destruirla y luego -inexplicablemente- no la destruye. En "Tlön, Uqbar, Orbis Tertius", relato despojado de personajes, retenemos la actitud del episódico Herbert Ashe que, según Borges, "padeció de irrealidad". Está "en el corredor del hotel, con un libro de matemáticas en la mano, mirando a veces los colores irrecuperables del cielo" (ibid., 17). De Funes el memorioso -quizá sea éste el mejor ejemplo- quedan dos actitudés difícilmente olvidables: Borges primero lo describe "con una oscura pasionaria en la mano, viéndola como nadie la ha visto". Y luego, antes de dar pruebas de su excepcional memoria:

Había oscurecido de golpe; oi rápidos y casi secretos pasos en lo alto; alcé los ojos y vi un muchacho que corría por la estrecha y rota vereda

25 "El delator, film", Sur, 1935, núm. 11, p. 90.

28 "Films", $D, 76$. 
como por una estrecha y rota pared. Recuerdo la bombacha, las alpargatas, recuerdo el cigarrillo en el duro rostro, contra un nubarrón ya sin límites (ibid., 118).

De "Funes el memorioso" retendrá el lector una situación, la del hombre que lo recuerda todo, pero igualmente retendrá esas dos actitudes, inexplicablemente satisfactorias, que no obedecen en apariencia a ninguna concatenación obvia. Actitudes que presenta Borges como circunstancias del relato: ahí está sin duda su encanto.

Este encanto del gesto circunstancial no se limita a los relatos de Borges. Cito sólo dos ejemplos tomados de sus ensayos. De Jesús, a quien llama el "mayor de los maestros orales", retiene por ejemplo "que una sola vez escribió unas palabras en la tierra y no las leyó ningún hombre" 27. De San Ambrosio, la actitud que sorprende San Agustín: "un hombre en una habitación, con un libro, leyendo sin articular las palabras" (ibid., 159).

He intentado señalar, a partir de los textos citados al principio, los dos polos entre los cuales parece oscilar el personaje borgeano. Por un lado la nadería de la personalidad, el personaje simulacro, el personaje texto, el personaje desdoblado, el yo de conjunto estrellado. Pero por el otro la necesidad de lo episódico y real, tal como lo veía en Hudson, que Borges aplica a la circunstancia del personaje, deteniéndose en detalles, en gestos, en actitudes que recomponen solapadamente a ese personaje. La tendencia más obvia -la única tendencia que le reconocen muchos de sus críticos- es la primera. Propongo que las dos son igualmente importantes en la obra de Borges. Que el personaje literario que nos ofrece, híbrido de mimesis y de objetos verbales, es un perfecto emblema de la tensión que nos propone toda su obra. Borges sabe que está "en literatura", nos lo dice en todo momento, nos lo recuerda, a través de ese personaje con el cual intentaríamos en vano identificarnos. Pero al mismo tiempo nos recuerda, saludablemente, la inevitable ilusión de realidad que plantea todo texto: nos la hace reconocer, aceptar con placer. Dice Borges del mundo: "lo hemos soñalo resistente, misterioso, visible, ubicuo en el espacio y firme en el tiempo; pero hemos consentido en su arquitectura tenues y eternos intersticios de sinrazón para saber que es falso" 28. De la misma manera parecería soñar Borges un relato firme y resistente en el que permite espacios, básicamente memorables, para minar la supersticiosa ética del lector que desatiende lo circunstancial, para finalmente postular una realidad narrativa que recupera al personaje no sólo como nexo sino como entidad eficaz del relato por su mera carga de asombro. "El arte - siempre- requiere irrealidades visibles" (loc. cit.), dice Borges. Y al comentar una vez más las aporías eleáticas declara que querría "conocer el nombre del poeta que las dotó de un héroe y de una tortuga" (ibid., 150).

Princeton University.

Sylvia Molloy

27 "Del culto a los libros", $O I, 158$.

28 "Avatares de la tortuga", $O I, 156$. 